\title{
Standing on the shoulders of giants
}

\author{
Samra Turajlic is a consultant medical oncologist at the Royal Marsden National Health Service Foundation Trust \\ and a clinician-scientist at the Francis Crick Institute.
}

\section{Samra Turajlic}

. uring my medical oncology training in 2007, I met a patient named Michael. He was 27 years old and newly diagnosed with advanced melanoma. Michael received chemotherapy, the only standard treatment available at that time. But his melanoma continued to spread to his liver and brain, and he died just three months after our first meeting.

Michael's story was not unusual. On average, patients diagnosed with metastatic melanoma survived for six to nine months, and chemotherapy was largely futile for this disease. Melanoma was often referred to as an 'orphan cancer' because of the lack of therapeutic progress for decades. This fueled my desire for a more fundamental understanding of the problem. I had not taken to laboratory research as an undergraduate. But at the time, new findings from basic research suggested that there may have been unexplored options for treatment of melanoma, so I wondered if I could help find answers by going back to the lab.

Preclinical evidence was emerging that inhibition of BRAF, a protein that usually stimulates cell growth, could be an effective treatment for melanoma. In 2002, scientists, including Richard Marais at the Institute of Cancer Research, discovered that mutations in the $B R A F$ gene drive the growth of melanoma tumors. Richard, along with Royal Marsden Hospital's leading oncologists Martin Gore and James Larkin, was investigating drugs that targeted melanomas with mutated BRAF. These three were also looking for a clinical $\mathrm{PhD}$ candidate who would not only train in basic science but also integrate the basic work with clinical research. The opportunity to work with them was a major turning point in my career and life.

The change didn't come easily. Being used to the fast pace of a clinic, I frequently attempted to run too many experiments at once, much to the amusement of my lab colleagues. The interface between the clinic and lab was immensely powerful, however. We were part of one of the finest (in my opinion) examples of research translation.

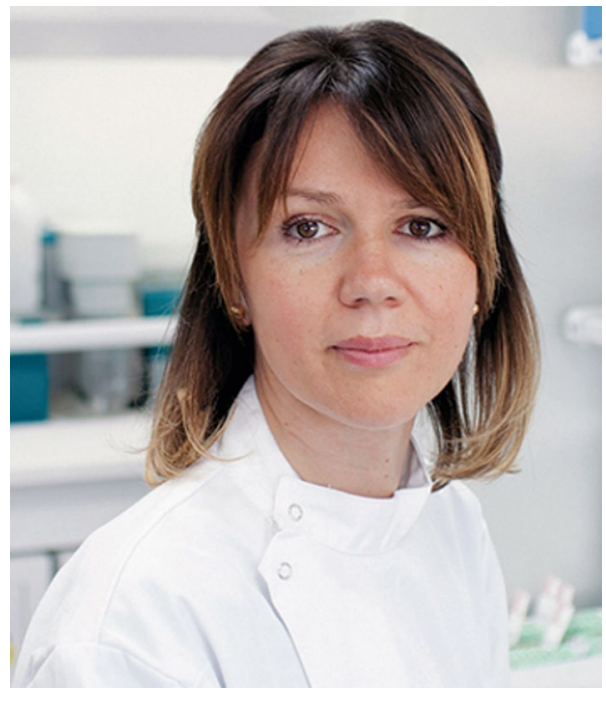

Credit: The Royal Marsden.

In the lab, we tested BRAF inhibitors using in vitro and in vivo models developed from patients' tumors. Simultaneously, these results were compared with responses of patients receiving BRAF inhibitors in clinical trials led by Martin and James. The treatment was working, sometimes spectacularly, which was revolutionary for an 'orphan cancer'.

I returned to oncology training after completing my $\mathrm{PhD}$ in 2013. There were a lot of myths surrounding clinicianscientists, including that we couldn't do authentic science or engage in meaningful clinical practice. Martin Gore was an essential mentor to me and was instrumental in boosting my career as a clinicianscientist. Martin argued that I use my knowledge of cell signaling and cancer genomics to tackle emerging clinical issues, such as resistance to therapies and the potential for harnessing the immune system to treat cancer. In our patients with BRAFmutant melanoma, resistance was inevitable, which was painful to witness. It became clear that resistance was a result of cancer's ability to evolve and adapt.
Martin and James were working with Charlie Swanton, also a clinician-scientist at the Francis Crick Institute, on cancer evolution. Joining his lab would be another turning point in my journey. We not only treated patients with melanoma, but also those who had renal cancer. The clinical course of renal cancer was bewilderingly varied, and I wondered whether this was underpinned by cancer evolution. Answering this question involved dozens of colleagues (clinical and academic) and our patients, whose commitment kept the project going through taxing times including collecting and analyzing thousands of cancer samples.

As I was writing this piece, Martin Gore died unexpectedly. For over ten years, Martin provided me with infinite kindness and wisdom, unconditional support and exceptional humor. He leaves a void that is impossible to fill, but I also realize how fortunate and privileged I am to have worked so closely with him. I would certainly not have become a clinician-scientist if it wasn't for Martin's championing. Martin taught me that clinical medicine and science were not so far apart, as many claimed. He argued that oncologists owed it to their patients to create research opportunities in the course of caring for them. As of today, the average survival of patients with metastatic melanoma is around four years, up from less than a year about a decade ago. This progress came about through a coordinated dedication of scientists, clinicians and patients, and this made Martin proud. I hope that through my involvement in clinical and basic science I can honor his legacy.

Samra Turajlic ${ }^{1,2}$

${ }^{1}$ The Renal and Skin Units, Royal Marsden NHS Foundation Trust, London, UK. ${ }^{2}$ The Cancer Evolution and Genome Instability Laboratory, The Francis Crick Institute, London, UK. e-mail:samra.turajlic@crick.ac.uk

Published online: 6 March 2019 https://doi.org/10.1038/s41591-019-0389-3 